\title{
DISERTACIONES
}

ESTUDIOS

Anuario electrónico de estudios en Comunicación Social

ISSN: $1856-9536$

Doi: dx.doi.org/10.12804/disertaciones.09.02.2016.05

Volumen 9, Número 2 / julio-diciembre 2016

Versión PDF para imprimir desde

http://revistas.urosario.edu.co/index.php/disertaciones

Para citar este artículo: Lazcano-Peña, D., \& Perry, A. (2016). Investigación en Comunicación en Chile: un mapa de su apoyo público, y la evidencia de su concentración. Anuario Electrónico de Estudios en Comunicación Social "Disertaciones", 9(2), 92-116. Doi: dx.doi.org/10.12804/disertaciones.09.02.2016.05

\section{INVESTIGACIÓN EN COMUNICACIÓN EN CHILE: UN MAPA DE SU APOYO PÚBLICO, Y LA EVIDENCIA DE SU CONCENTRACIÓN}

Communication Research in Chile: A Map of Public Funding and Evidence of its Concentration

Investigação em Comunicação no Chile: um mapa de seu apoio público, e a evidência da sua concentração

\author{
Lazcano-Peña, Daniela. Pontificia Universidad Católica de Valparaíso (Chile) \\ daniela.lazcano@pucv.cl
}

Perry, Alejandro. Pontificia Universidad Católica de Valparaíso (Chile)

alejandro.perry.v@mail.pucv.cl

Fecha de recibido: 06 de noviembre de 2015

Fecha de aprobado: 13 de abril de 2016

\section{RESUMEN}

¿Qué lugar ocupa el estudio de la Comunicación en el conocimiento científico del país? ¿Qué temáticas predominan en los intereses de los investigadores? ¿Cómo se ubica el apoyo a esta disciplina en relación con otras áreas o campos académicos? Estas preguntas son el hilo conductor del presente artículo, que busca aportar a la cartografía del campo de la Comunicación en Chile, por medio de una de sus aristas específicas: su investigación científica. En concreto, el texto presenta los resultados de un análisis cuantitativo de las bases de datos del principal organismo público de financiamiento a la investigación en Chile: la Comisión Nacional de Ciencia y Tecnología 


\title{
DISERTACIONES
}

ESTUDIOS

Anuario electrónico de estudios en Comunicación Social

ISSN: $1856-9536$

Doi: dx.doi.org/10.12804/disertaciones.09.02.2016.05

Volumen 9, Número 2 / julio-diciembre 2016

Versión PDF para imprimir desde

http://revistas.urosario.edu.co/index.php/disertaciones

(Conicyt) y su Fondo Nacional de Desarrollo Científico y Tecnológico (Fondecyt), considerado en la actualidad como una de las fuentes más importantes para el fomento a la generación de conocimiento, innovación y desarrollo en el país. Como principales resultados, durante el periodo analizado (1982-2014) se evidencia la escasa presencia del área de las Ciencias de la Comunicación e Información en los presupuestos generales del organismo, y una marcada tendencia a la concentración de las investigaciones financiadas, considerando tanto instituciones e investigadores responsables, como temáticas y objetos de estudios.

Palabras clave: metainvestigación, investigación en Comunicación, Chile, campo académico.

\begin{abstract}
Where does the Communications study stand in the development of the country's scientific research? Which topics predominate among the interests of researchers? How is the support to this discipline in comparison to other areas or academic fields? These questions represent the main idea of this article, which seeks to contribute to the Communications field in Chile through one of its specific edges: the scientific research. This paper presents the results of a quantitative analysis made to the main public funding institution for research in Chile's database: the National Commission of Science and Technology (Conicyt) and its National Scientific and Technological Fund (Fondecyt). This institution is nowadays considered as one of the most important sources for the promotion of knowledge production, innovation and development of the country. As main results, this study shows the limited presence of the Science Communication and Information's field on the institution's general budget, and a high trend to concentration in terms of institutions, researchers and objects of study.
\end{abstract}

Keywords: Meta-research, Communication Research, Chile, academic field.

\section{RESUMO}

Que lugar ocupa o estudo da Comunicação no conhecimento científico do país? Que temáticas predominam nos interesses dos pesquisadores? Como se encontra o apoio a esta disciplina em relação com outras áreas ou campos acadêmicos? Estas perguntas são o fio condutor do presente artigo, que busca aportar à cartografia do campo da Comunicação no Chile, por meio de uma das suas aristas específicas: a sua investigação científica. Em concreto, o texto apresenta os resultados de uma análise quantitativa das bases de dados do principal organismo público de financiamento à investigação no Chile: a Comissão Nacional de Ciência e Tecnologia (Conicyt) e o seu Fundo Nacional de Desenvolvimento Científico e Tecnológico (Fondecyt), considerado na atualidade como uma das fontes mais importantes para o fomento à geração de conhecimento, inovação e desenvolvimento no país. Como principais resultados, durante o período analisado (1982-2014) se evidencia a escassa presença da área das Ciências da Comunicação e Informação nos orçamentos gerais do organismo, e uma marcada tendência à con- 


\section{DISERTACIONES}

ESTUDIOS

Anuario electrónico de estudios en Comunicación Social

ISSN: $1856-9536$

Doi: dx.doi.org/10.12804/disertaciones.09.02.2016.05

Volumen 9, Número 2 / julio-diciembre 2016

Versión PDF para imprimir desde

http://revistas.urosario.edu.co/index.php/disertaciones

centração das investigações financiadas, considerando tanto instituições e investigadores responsáveis, quanto temáticas e objetos de estudos.

Palavras-chave: Meta-investigação, investigação em Comunicação, Chile, campo acadêmico.

\section{Antecedentes}

Si bien, en el contexto de las ciencias sociales, el estudio de la Comunicación puede ser considerado un campo disciplinario joven, los últimos años han sido testigos de su rápido crecimiento y consolidación. Así, se ha transitado de unas iniciales preocupaciones - provenientes de investigadores de la sociología, filosofía, o psicología social-centradas en los efectos del uso propagandístico de los medios de Comunicación en los años veinte del siglo xx, a la materialización de una comunidad científica y académica activa y expandida en distintas partes del mundo. $Y$ todo, en corto tiempo:

Hace un siglo no había comunicología, en sentido estricto no había teoría de la comunicación. No había campo académico con esos nombres. No había escuelas universitarias ni grupos de estudio. No había centros de investigación con ese objeto. No había redes de investigadores. No había presupuestos oficiales para su exploración y desarrollo. No había debates en su nombre, no había espacios de divulgación pública. No había revistas, ni boletines, ni congresos, ni reuniones, ni postgrados, ni campo profesional. Solo había algunas ideas, algunos apuntes, curiosidades, visiones. Y cien años después todo ha cambiado, este es un campo académico profesional en auge, en emergencia explosiva, ocupando la primera línea de todas las agendas políticas y económicas, en el corazón de los debates culturales. Algo pasó, algo que ha modificado al planeta, algo que nos ha transformado en el centro y aún no despertamos de la sorpresa (Galindo, 2009, pp. 95-96).

Esta tendencia global, o al menos internacional, se evidencia también en el espacio en que se ha centrado la observación de este artículo: Chile. Los primeros antecedentes de la conformación de un campo académico entorno a la Comunicación en el país pueden remontarse o fecharse en dos hitos, los años treinta, época de la que datan las primeras reflexiones académicas tipo ensayo sobre la influencia de los medios en la opinión pública (Munizaga \& Rivera, 1983) y -varios años después - la década de los cincuenta, con la creación de la primera escuela de Periodismo, en la Universidad de Chile (González, 2001), lo que marca un paso relevante en la conformación de una comunidad académica.

Sin embargo, y haciendo un poco de revisión histórica, lejos de estos inicios, es a mediados de la década de los ochenta y principios de los noventa, cuando el campo de la Comunicación comienza un proceso de crecimiento en el país: nacen las primeras revistas especializadas de la disciplina (Comunicación y Medios, de la Universidad

\section{4}




\section{DISERTACIONES}

Estuolos

Anuario electrónico de estudios en Comunicación Social

ISSN: $1856-9536$

Doi: dx.doi.org/10.12804/disertaciones.09.02.2016.05

Volumen 9, Número 2 / julio-diciembre 2016

Versión PDF para imprimir desde

http://revistas.urosario.edu.co/index.php/disertaciones

de Chile, en 1981, y Cuadernos de Información - actualmente Cuadernos.info- de la Pontificia Universidad Católica de Chile, en 1986), y la oferta académica de programas de grado y posgrado relacionada con el área inicia su periodo de auge; en la actualidad, los estudiantes interesados en estudiar el grado en Periodismo en Chile pueden optar a alguna de las 27 universidades ( $45 \%$ del total de 59 casas de estudio existentes en el país) que oferta este programa a nivel de licenciatura. En posgrado, en tanto las posibilidades se extienden a 32 magíster y dos programas de doctorado: el Doctorado en Ciencias de la Comunicación de la Pontificia Universidad Católica de Chile, creado en 2012; y el de la Universidad del Desarrollo que este 2016 ofrecerá su primera versión.

Estos datos, sumados a otros antecedentes como la recientemente creada Incom, Asociación Chilena de Investigadores en Comunicación - que este 2016 ya está organizando el tercer congreso nacional de la materia-, permiten también proyectar y comprender el campo de la Comunicación como una disciplina en creciente desarrollo y articulación.

Tomando este marco como contexto, este texto nace con el propósito de aportar a la configuración de una cartografía sobre el campo de la Comunicación en Chile, asumiendo como supuesto o declaración inicial que el ejercicio de meta-investigación de una determinada comunidad académica implica un aporte para reflexionar sobre qué es lo que se ha hecho o se está haciendo, y cómo se puede hacer una proyección y crecer. Implica además, un reconocimiento a un determinado estado de madurez y a un camino recorrido.

El interés por considerar la propia disciplina como objeto de estudio se inspira, como sustento teórico, en la noción de campo planteada por Bourdieu (1997), quien lo define como:

Un espacio social estructurado, un campo de fuerzas - hay dominantes y dominados, hay relaciones

constantes, permanentes, de desigualdad, que se ejercen al interior de ese espacio-que es también un

campo de luchas para trasformar o conservar este campo de fuerzas (p. 57).

Llevando esta definición general al ámbito específico de la Comunicación, la autora brasileña Vasallo de Lopes (2001) comprende el campo académico de la Comunicación como "un conjunto de instituciones de educación superior destinadas al estudio y a la enseñanza de la comunicación, donde se produce la teoría, la investigación y la formación universitaria de los profesionales de la comunicación" (p. 44). Este campo académico se divide, a la vez, en varios subcampos:

El científico, implicado en prácticas de producción de conocimiento: la investigación académica tiene la finalidad de producir conocimiento teórico y aplicado por medio de la construcción de objetos, metodologías y teorías; el educativo, que se define por prácticas de reproducción de ese conocimiento, es decir, mediante la enseñanza universitaria de materias relacionadas con la comunicación; y el profesional, caracterizado por prácticas de aplicación del conocimiento y que promueve vínculos variados con el mercado de trabajo (Vasallo de Lopes, 2001, p. 44).

Siguiendo a Bourdieu (1997), Vasallo de Lopes (2001) sustenta esta estructura como:

Un campo de prácticas institucionalizadas de producción (investigación), reproducción (enseñanza) y circulación de capital y poder científicos. Debido a la distinción trazada entre formas objetivadas de las prácticas (rituales) y formas subjetivadas de esas prácticas (estructuras mentales interiorizadas, es decir, habitus), es posible identificar ahí lo que otros autores trabajan como representaciones sociales (Moscovici). Las representaciones sociales de la ciencia funcionan como materia prima de las identidades científicas, fruto de las formas simbólicas introyectadas, es decir, de la cultura científica interiorizada (p. 47). 


\section{DISERTACIONES}

Estudios

Anuario electrónico de estudios en Comunicación Social

ISSN: $1856-9536$

Doi: dx.doi.org/10.12804/disertaciones.09.02.2016.05

Volumen 9, Número 2 / julio-diciembre 2016

Versión PDF para imprimir desde

Tomando estos elementos, se puede entender que el análisis del campo de la Comunicación, y de aquellos elementos en que se expresa su quehacer, entregaría información sobre sus principales tendencias o características. Es decir, permitiría comprender la disciplina desde su interior, para sistematizar datos de contexto que enmarquen o doten de sentido sus dinámicas y desarrollo.

En este sentido, el propósito de esta investigación será aportar al conocimiento de una de estas aristas del campo, vinculada en específico al subcampo científico, es decir, a la generación de conocimiento en la disciplina.

Para acotar empíricamente esta aproximación, metodológicamente la investigación se enmarcará en la caracterización de la investigación en Comunicación realizada en Chile con apoyo de una de sus principales fuentes de financiamiento público: la Comisión Nacional de Ciencia y Tecnología (Conicyt), entidad creada en la década de los ochenta para impulsar el desarrollo del conocimiento científico, y donde uno de sus programas de fomento, el Fondo Nacional de Desarrollo Científico y Tecnológico (Fondecyt), es considerado por evaluaciones nacionales e internacionales como un elemento clave en el desarrollo científico y tecnológico del país.

Así, el objetivo de esta investigación será analizar y caracterizar la investigación vinculada al campo de la Comunicación en Chile apoyada por este fondo concursable, por medio de la sistematización de elementos como sus principales temáticas, distribución institucional y posición en relación con otras disciplinas o áreas de conocimiento.

\section{Investigación made in Chile}

Si bien la discusión metateórica sobre el campo de la Comunicación cuenta con amplia y reconocida producción científica internacional, con textos clásicos como los de Wolf (1987), McQuail (1991), Mattelart y Mattelart (1995), Rodrigo-Alsina (2001), Moragas (2011) o Saperas (2012), entre muchos otros, en el caso de Chile, estas revisiones ofrecen un escenario bibliográfico acotado, pero creciente en los últimos años.

Así, entre 1983 - fecha de la primera publicación vinculada a esta materia- y el año 2000, solo es posible identificar cuatro trabajos dedicados a la conformación de un mapa sobre el campo de la Comunicación en Chile: "La investigación en Comunicación social en Chile" (1983) de Giselle Munizaga y Anny Rivera, donde las autoras abordan el desarrollo del campo entre 1930 y 1973; "Contenidos temáticos de la formación en Comunicación" de Edison Otero (1996); "Las ong y la investigación en comunicaciones en Chile: una aproximación preliminar" de Carlos Catalán (1989); y la exposición "Transformaciones en la investigación en comunicación. El caso de Chile", presentada por Claudio Avendaño (1998), en el ॥ Ciclo de Estudios sobre Comunicación de la Universidad Metodista de São Paulo.

Sin embargo, en los últimos quince años el interés de los investigadores por estudiar el desarrollo del propio campo ha vivido un creciente auge, con la aparición de nuevos trabajos: Del Valle (2004a), quien realiza un catastro de las investigaciones y libros publicados en el país desde los años setenta hasta el 2003 bajo la mirada de la economía política; Castellón (2006), quien revisa desde una perspectiva histórica el contexto que enmarca la investigación y formación de comunicadores en Chile; Lazcano-Peña (2007), quien aborda las principales tendencias de investigación de las tesis de pregrado de la Escuela de Periodismo de la Pontificia Universidad Católica de Valparaíso; Dittus (2008) quien, desde una perspectiva semiótica, construye una cartografía de los estudios realizados en Chile desde la mediología; y Caldevilla y Del Valle (2011), quienes estudian el estado y condiciones de difusión - grado de conocimiento de los sistemas de indización y repercusión en su trabajo- del trabajo de 


\section{DISERTACIONES}

ESTUDIOS

Anuario electrónico de estudios en Comunicación Socia

ISSN: $1856-9536$

Doi: dx.doi.org/10.12804/disertaciones.09.02.2016.05

Volumen 9, Número 2 / julio-diciembre 2016

Versión PDF para imprimir desde

http://revistas.urosario.edu.co/index.php/disertaciones

investigadoras chilenas en Comunicación. A estas investigaciones se suman, además, los trabajos de titulación de magíster de Olivares (2011) y Jeldres (2014).

Considerando esta bibliografía, es posible trazar un mapa de la investigación en Comunicación ubicando como punto inicial la década del treinta, cuando surgen "los primeros gérmenes de interés científico en el tema" (Munizaga \& Rivera, 1983, p. 13). Desde esos años, y hasta fines de los años cincuenta, el periodo estaría marcado por la gestación del aparato comunicacional en el país: la mayor urbanización y alfabetización de la población generó el incremento en el consumo de medios, la prensa y la radio viven una creciente industrialización en los años cuarenta, y ya en la década de los cincuenta los medios alcanzan gran parte de la población urbana, en especial en sectores de clase media y alta, y en grupos políticamente activos.

En este contexto, y también derivado del interés que en el ámbito internacional había generado el uso propagandístico de los medios de comunicación en las Guerras Mundiales, estos:

comienzan a ser percibidos no solo en su función de entretención e información, sino como formadores de

opinión pública. En una sociedad como la chilena, con un desarrollado juego político público, esta función

adquiría, sin duda, una relevancia enorme. La extensión de la cobertura de los medios los transforma,

entonces, en herramientas de primer orden para el desarrollo del proceso político y, en especial, para las

coyunturas electorales (Munizaga \& Rivera, 1983, p. 14).

Según registran estas autoras, los trabajos de investigación de esta época no alcanzan a configurar un campo académico como tal, sino que se tratan más bien de ensayos esporádicos que dan cuenta de la preocupación de algunos intelectuales sobre el potencial efecto de los medios en el manejo de la opinión pública.

Tras este momento fundacional, la década de los sesenta trae consigo un impulso al campo de las ciencias sociales en general, y de la comunicación en particular, no solo en Chile, sino también en el resto del continente latinoamericano: son los años de la irrupción de la televisión, y la influencia de la Teoría Desarrollista.

Se trata de una primera fase marcada por las teorías de la psicología conductista y la sociología funcionalista, en otras palabras por el marco teórico de la Communication Research norteamericana. Y es en esta etapa donde se desarrollaron numerosos estudios cuantitativos de audiencias y de opinión pública, realizados a partir de intereses comerciales de diversas empresas patrocinadoras. La creación del Centro Internacional de Estudios Superiores de Comunicación para América Latina (CIESPAL), en Quito, en 1959, como centro de estudios de la comunicación social latinoamericana, se transformó en un fuerte estímulo para delimitar el campo investigativo y para la creación de facultades de comunicación (Dittus, 2008).

Sin embargo, y por contrapartida a estas tendencias teóricas marcadas por la influencia del funcionalismo estadounidense, adquieren protagonismo

[...] un grupo de investigadores y académicos comienzan a transformar su malestar con las teorías sobre

el desarrollo del carácter lineal y desarrollista. Fernando Enrique Cardoso, Enzo Falletto, Osvaldo Sunkel,

Raúl Prebish proponen un enfoque alternativo: la teoría de la dependencia. Este nuevo enfoque modifica

la forma de mirar el proceso comunicacional. Por una parte, se comienza a utilizar el estructuralismo para

develar los componentes ideológicos de los programas de televisión y la prensa (Castellón, 2006).

Esta mirada crítica, estrechamente marcada, además, por el fuerte compromiso ideológico con los cambios sociales fue una de las características que marcó a los investigadores en comunicación en el país, tendencia acentuada durante el Gobierno de la Unidad Popular (Lazcano-Peña, 2007), encabezado por el presidente socialista 


\section{DISERTACIONES}

ESTUDIOS

Anuario electrónico de estudios en Comunicación Social

ISSN: $1856-9536$

Doi: dx.doi.org/10.12804/disertaciones.09.02.2016.05

Volumen 9, Número 2 / julio-diciembre 2016

Versión PDF para imprimir desde

http://revistas.urosario.edu.co/index.php/disertaciones

Salvador Allende y que, en términos de investigación, se orientó hacia ámbitos como la comunicación educativa, el análisis de los discursos, los estudios culturales, la economía política de los medios masivos; así, los primeros estudios sobre el cómic son considerados clásicos para la disciplina (Dittus, 2008). De esta época, por ejemplo, es uno de los mayores clásicos de la producción nacional: Para leer al Pato Donald, de Armand Mattelart y Ariel Dorffman, publicado en 1972.

En este periodo y de acuerdo con Avendaño (1998), este énfasis ideológico se vive en un escenario de contradicción en que, de manera cotidiana, convivían

[...] el análisis de programas como "El fBI en acción", "Bonanza", "Misión imposible" y otras series norteamericanas obedecía a la contradicción entre televidentes asiduos a ciertos programas y la propuesta anti-imperialista que estos mismos "receptores" propugnaban. Probablemente, después de gritar "yanki go home" o de quemar una bandera se instalaban a ver estos programas, que además resultaban los más vistos (p. 46).

El componente político ideológico de este periodo se observa también en ciertas perspectivas teóricas que irrumpen y predominan en la investigación en comunicación: semiótica o semiología, economía política de las industrias culturales, comunicación educativa e historia social de comunicación (Lazcano-Peña, 2007).

En general, la investigación en comunicación durante este periodo fue específica y original, con énfasis en variables ideológicas. Fueron habituales los estudios críticos sobre la producción televisiva estadounidense y sus aspectos ideológicos y sobre las lógicas de consumo, particularmente a partir de la contradicción entre formas de recepción: receptores asiduos y receptores críticos, incluso antiimperialistas, una problemática no menor que, actualmente, tiende a ser estudiada desde una perspectiva solo de producción; esto es, desde los intereses de la instancia emisora-productora (Del Valle, 2004a).

Este contexto de fructífero desarrollo de la investigación en Comunicación sufrió - como muchas otras áreas y dimensiones del país - la fuerte arremetida del Golpe Militar, que el 11 de septiembre de 1973 derrocó el Gobierno de Salvador Allende, dando inicio a 17 años (hasta 1989) de dictadura y fuerte represión política y social. Este quiebre institucional, también generó efectos en el campo de la Comunicación: "la mayoría de los centros se cierran, las escuelas de periodismo cambian su orientación, que se torna fundamentalmente técnica. Esto hace que la investigación se quede, por algún tiempo, en suspenso" (Del Valle, 2004a, p. 72).

A pesar del declive que vive la investigación en Comunicación -y el desarrollo científico en general- en el país, cuando esta se retoma, se hace en una "doble orientación" (Del Valle, 2004a): por un lado, la tendencia a una investigación más formal orientada a ámbitos menos ideológicos (estudios históricos y descriptivos) y, por otra, el importante aporte de análisis críticos impulsados por las sedes nacionales de instituciones internacionales -como la Facultad Latinoamericana de Ciencias Sociales (FLACSO), por ejemplo- y las emergentes Organizaciones No Gubernamentales (ong) que operaron como espacios de resistencia y oposición al gobierno de Pinochet, muchos de ellos con financiamiento de organismos extranjeros (Lazcano-Peña, 2007).

En estos espacios, que albergaron a la mayoría de los investigadores en comunicación ante la imposibilidad de integrarse a las universidades tradicionales (Castellón, 2006), la agenda de investigación, en esos años, y en coherencia con el contexto político nacional, se concentró en "comprender el accionar comunicativo monopólico del gobierno militar y su proyecto neoliberal y, al mismo tiempo, acompañar las prácticas comunicativas de ciertos sectores, como los estudiantes, sindicalistas y pobladores de sectores populares" (Avendaño, 1998), dando 


\section{DISERTACIONES}

Estudios

Anuario electrónico de estudios en Comunicación Social

ISSN: 1856-9536

Doi: dx.doi.org/10.12804/disertaciones.09.02.2016.05

Volumen 9, Número 2 / julio-diciembre 2016

Versión PDF para imprimir desde

paso a temáticas como políticas de comunicaciones del gobierno militar, comunicación alternativa y estudios sobre recepción (Castellón, 2006).

Con la recuperación de la democracia -el plebiscito que dijo "No" a la continuidad de Pinochet en el gobierno tuvo lugar el 5 de octubre de 1988, y las elecciones que llevaron a la presidencia al demócrata cristiano Patricio Aylwin se realizaron el 14 de diciembre de 1989, lo que marcó el inicio del denominado proceso de transición a la democracia-, el campo de la Comunicación vivió un nuevo giro en su estructura e intereses. Así, "a finales de la década del noventa, y en consonancia con la apertura democrática, comienza a debatirse e investigarse sobre el proyecto comunicacional del futuro gobierno democrático y el funcionamiento del sistema medial en una economía de mercado" (Castellón, 2006).

Además, la llegada de la democracia trajo consigo el declive de las onG, por la migración de sus profesionales a otros espacios: universidades tradicionales y privadas, centros de estudios como Fundación Chile 21 o el Instituto Libertad y Desarrollo (vinculados ambos a las principales colisiones de partidos políticos, de centro-izquierda y centro-derecha, respectivamente); organismos estatales como el Consejo Nacional de Televisión y la Secretaría General del Gobierno; y consultoras profesionales de comunicación, orientadas principalmente al sector privado y a la percepción de climas de opinión mediante encuestas.

\section{El impulso público del desarrollo científico en Chile}

Esta estructura del campo de la Comunicación es, en términos generales, la composición que se mantiene hasta el día de hoy, y desde donde se desarrolla la formación e investigación científica vinculada con la disciplina.

En esta última arista, el Estado chileno es uno de los agentes impulsores clave de la generación de nuevo conocimiento, en especial por medio de su Comisión Nacional de Investigación Científica y Tecnológica (Conicyt), tanto en el campo de la Comunicación -donde las Ciencias de la Comunicación e Información están categorizadas como subdisciplinas específicas de apoyo dentro del área de Sociología.

Dependiente del Ministerio de Educación, Conicyt fue creado en 1967 como organismo asesor de la Presidencia en materias de desarrollo científico. Desde esa definición, en los últimos 49 años ha sido fundamental en el fortalecimiento de la ciencia y tecnología en Chile, al apoyar iniciativas y orientar sus esfuerzos al objetivo final de contribuir al progreso económico, social y cultural del país.

Este rol es reconocido por la propia comunidad vinculada al desarrollo de la ciencia en Chile, quienes, en un reciente estudio sobre satisfacción de la política pública de fomento de la investigación científica, valoran el aporte de los fondos públicos provenientes de este y otros organismos, frente a otras fuentes de financiamiento como los fondos de las propias universidades - de menor escala, en general asociados con la complementación de fondos producto de la adjudicación de algún fondo concursable, y restringidos "a pocas casas de estudio que poseen recursos, valoran y promueven el desarrollo de la ciencia por el prestigio que ello les reporta" (Asesorías para el Desarrollo, 2012, p. 36)-, o los provenientes de fondos internacionales - los que serían de difícil acceso "pues Chile se encuentra en una posición compleja que lo deja al margen de fondos por ser un país en vías de desarrollo y donde, a la vez, no logra participar de otros fondos destinados a los países que hacen aportes significativos al desarrollo científico" (Asesorías para el Desarrollo, 2012, p. 35). Esta situación se acrecentaría en el caso de las ciencias sociales -donde se ubican los estudios de Comunicación - en los que "el financiamiento para el desarrollo investigativo 


\section{DISERTACIONES}

Estudios

Anuario electrónico de estudios en Comunicación Social

ISSN: 1856-9536

Doi: dx.doi.org/10.12804/disertaciones.09.02.2016.05

Volumen 9, Número 2 / julio-diciembre 2016

Versión PDF para imprimir desde

es escaso, pues el mayor financiamiento se dirige a temas productivos. Así aparece Conicyt como una fuente casi exclusiva de financiamiento para el área social” (Asesorías para el Desarrollo, 2012, p. 37).

En cuanto a su funcionamiento, a partir de 1980-1981, el Gobierno de Chile introdujo la modalidad de fondos concursables como criterio para la asignación de sus propios recursos en las áreas de educación superior y desarrollo científico y tecnológico. Así, en 1981 se creó el primero de ellos: el Fondo Nacional de Desarrollo Científico y Tecnológico (Fondecyt), programa público administrado por Conicyt que es hasta hoy el principal fondo público de apoyo a la investigación individual en Chile, orientado a mantener la política pública de asignación de recursos para la investigación científica básica sobre la base de concursos públicos y competitivos.

En concreto, Fondecyt se traduce en el soporte financiero a un investigador para la ejecución de proyectos de entre 2 y 4 años de duración. Este instrumento cuenta con tres convocatorias específicas: Regular, orientado a investigadores con trayectoria, y donde un investigador responsable puede participar junto con un grupo pequeño de coinvestigadores; Iniciación en Investigación, orientado a investigadores jóvenes que hayan obtenido el grado de doctor en los últimos cinco años; y proyectos de posdoctorado. Cada una de estas líneas se organiza en convocatorias concursables anuales, y se pueden postular proyectos en todas las áreas del conocimiento.

Además de Fondecyt, Conicyt tiene otros doce programas que apoyan el fortalecimiento de la ciencia y tecnología en Chile. Sin embargo, y a pesar de esta diversidad de líneas de apoyo a la innovación e investigación, Fondecyt ha logrado el reconocimiento de la comunidad científica chilena como uno de los instrumentos de mayor relevancia en el desarrollo científico-tecnológico nacional. Esto, debido al número y calidad de los científicos que han participado, participan y participarán en él, junto con las numerosas innovaciones que ha introducido, el número de proyectos que ha financiado y el impacto significativo que ha tenido en el desarrollo de los estándares de calidad y cantidad de investigación científica-tecnológica nacional.

Evaluaciones nacionales e internacionales realizadas al Programa, como BID (1997), DIPRES (1998), IDRC- Canadá (1999), concuerdan en que hoy sería impensable el desarrollo científico y tecnológico del país sin un instrumento de financiamiento y estímulo a la investigación como Fondecyt.

\section{Objetivos y metodología}

En este contexto, y considerando la relevancia de Fondecyt para el desarrollo del conocimiento científico en el país, se da la pregunta por el lugar que, en la historia de este fondo, ha ocupado en este el campo de la Comunicación.

A partir de esta pregunta, en este artículo se ha propuesto como objetivo analizar la investigación vinculada al campo de la Comunicación en Chile, cuya ejecución ha sido apoyada por este fondo concursable. Se piensa que por medio de este ejercicio se podrá aportar con una panorámica de las tendencias de apoyo público -materializado en financiamiento- que ha concitado la investigación y el desarrollo de la disciplina en el país.

Para alcanzar este propósito interesa:

(a) Identificar los proyectos vinculados con la disciplina que se han financiado por medio de este fondo.

(b) Ubicar la posición relativa que el apoyo a estos proyectos ocupa en relación con otras disciplinas o áreas de conocimiento.

(c) Caracterizar las principales tendencias de los proyectos financiados por este fondo en la disciplina, considerando las temáticas y la distribución institucional, por ejemplo. 


\section{DISERTACIONES}

Estudios

Anuario electrónico de estudios en Comunicación Social

ISSN: 1856-9536

Doi: dx.doi.org/10.12804/disertaciones.09.02.2016.05

Volumen 9, Número 2 / julio-diciembre 2016

Versión PDF para imprimir desde

En términos metodológicos, se realizó un análisis cuantitativo a partir de las bases de datos y documentos públicos que ofrecen información sobre Fondecyt, disponibles en el sitio web de la institución (www.conicyt.cl), en especial la serie de documentos "Panorama científico Fondecyt" publicados anualmente, y cuya última edición da cuenta de los resultados del fondo durante 2014. A partir de la revisión y sistematización de toda aquella información que diera cuenta sobre los fondos destinados a proyectos relacionados con el campo de la Comunicación, se establecieron los siguientes criterios de selección del corpus de análisis:

(a) Limitación temporal de la muestra al periodo comprendido entre 1982 y 2014, considerando el año de inicio del fondo y el último año con información completa en bases de datos ${ }^{1}$.

(b) Revisión solo de la línea de apoyo denominada Fondecyt Regular, sin incluir las de Iniciación y Posdoctorado, pues son de reciente creación, por lo que no están presentes en todo el periodo de la muestra.

(c) Acotación de los proyectos incluidos en este estudio a solo aquellos que explícitamente postularan como disciplina principal en la línea de Ciencias de la Comunicación e Información, subdisciplina del campo de la Sociología, y equivalente a las disciplinas Ciencias Sociales/Comunicación y Medios en la tipología de la Organización para la Cooperación y el Desarrollo Económicos (OCDE)².

\section{Resultados}

\subsection{El campo de la Comunicación en la mirada de Fondecyt}

Las postulaciones y adjudicaciones de proyectos Fondecyt se organizan en Grupos de Estudio de acuerdo con las áreas disciplinarias. En la actualidad existen 26 grupos en las diferentes disciplinas: Ciencias Exactas y Naturales (8 grupos); Tecnología y Ciencias de la Ingeniería (3 grupos); Tecnología y Ciencias Silvoagropecuarias (2 grupos); Ciencias jurídicas, económicas y administrativas (2 grupos); Humanidades (3 grupos); y Tecnología y Ciencias Médicas (3 grupos). A estas áreas se suma la de Ciencias Sociales que alberga 5 grupos de estudio: Antropología y arqueología; Educación; Arquitectura, urbanismo, geografía y artes; Psicología y Sociología.

Los estudios sobre Comunicación forman parte del Grupo de Sociología, con la denominación de Ciencias de la Comunicación e Información. Como campo, comparten grupo con otras 9 subdisciplinas: Cambio social y desarrollo; Metodología; Sociología de las organizaciones formales; Sociología Urbana y Rural; Teoría socio-cultural; Sociología del trabajo; Política científica y tecnológica; Trabajo social; y Otras sociologías.

1 Si bien, a la fecha de elaboración, revisión y publicación de este artículo, ya se habían conocido los resultados del concurso Fondecyt Regular de los años 2015 y 2016, se tomó la decisión de no incluirlos en la muestra debido a que la información pública disponible no especificaba la subdisciplina de adjudicación, sino que consideraba solo la referencia general al área de conocimiento, por lo que no era posible identificar, en específico, cuáles de los proyectos aprobados en el área de Sociología, correspondían a la subdisciplina de Ciencias de la Comunicación e Información.

2 Es necesario advertir que, si bien es posible encontrar investigaciones vinculadas con el campo de la Comunicación aprobadas en áreas afines como "Historia" u "Otras sociologías", por ejemplo, no se han incluido en este estudio. Se fundamenta esta decisión metodológica en la posibilidad de configurar, delimitar y abordar la muestra a la línea que de manera mayoritaria congrega -o debería congregar- las iniciativas del área. 


\section{DISERTACIONES}

Estudios

Anuario electrónico de estudios en Comunicación Social

ISSN: $1856-9536$

Doi: dx.doi.org/10.12804/disertaciones.09.02.2016.05

Volumen 9, Número 2 / julio-diciembre 2016

Versión PDF para imprimir desde

http://revistas.urosario.edu.co/index.php/disertaciones

Con base en estas categorías, se revisaron las bases de datos e informes sobre resultados de Fondecyt Regular para identificar los proyectos aprobados bajo la categoría de Ciencias de la Comunicación e Información.

A partir de esta revisión, se tiene el primer resultado de esta investigación: entre los años 1982 -fecha de la creación del fondo- y 2014 se aprobaron un total de 45 proyectos en el área de Ciencias de la Comunicación e Información. El primero de ellos se adjudicó recién el año 1987 -5 años después de la primera versión del concurso-correspondiendo al estudio “La televisión en Chile", a cargo de la investigadora María de la Luz Hurtado, del Centro de Comunicación y Cultura para el Desarrollo³.

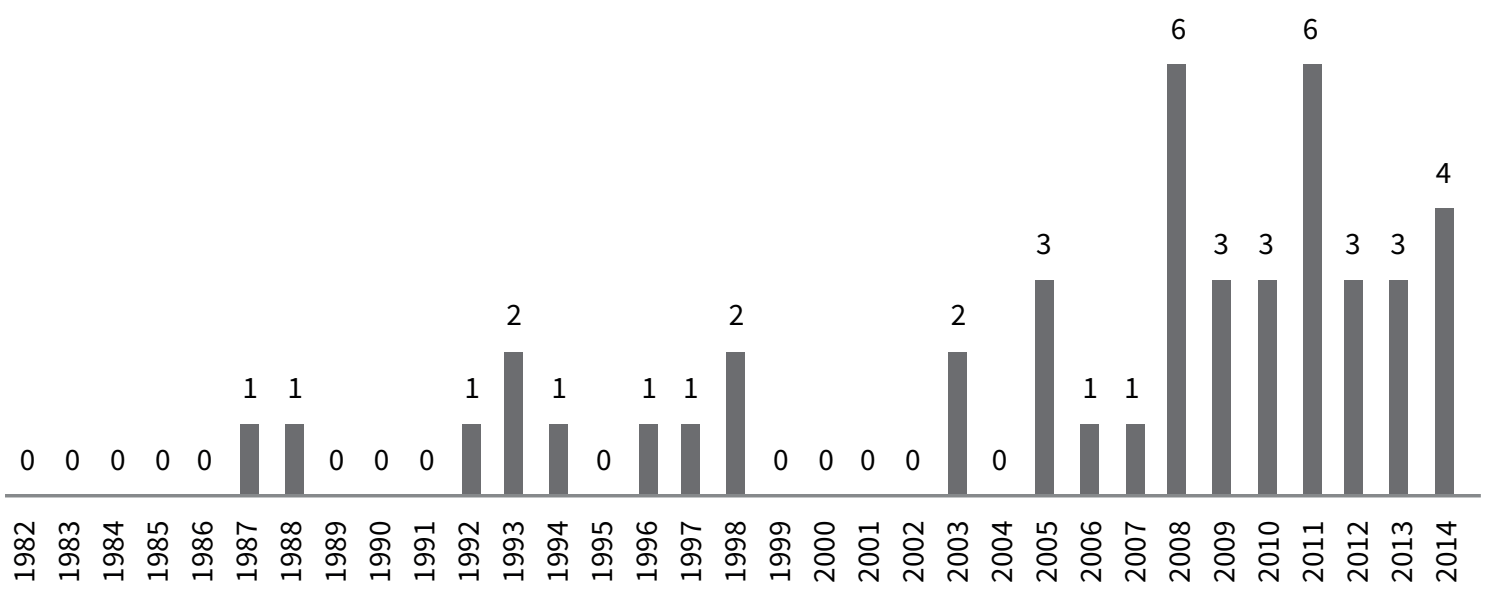

Figura 1. Proyectos Fondecyt aprobados en el campo de la Comunicación por año (1982-2014)

A partir de los datos, se puede observar también que no es sino hasta el año 2005 cuando la disciplina comienza a adjudicarse proyectos con mayor regularidad, considerando esta regularidad como presencia anual de proyectos del área entre las iniciativas favorecidas por el fondo, mas no como número de iniciativas aprobadas, las que varían entre una, tres, o seis por año. Este dato solo se puede evidenciar a nivel descriptivo, pues faltan elementos para aventurar alguna observación o conclusión a partir de la cifra, ya que no se sabe, por ejemplo, si aquellos años en que no se aprobaron iniciativas hubo, o no, presentación de proyectos en el área que pudieran haber sido rechazadas.

A pesar de eso, sí se pueden aportar algunos elementos de contexto, y es que la tasa de adjudicación de los proyectos presentados en el área de Ciencias Sociales, donde se ubica Comunicación e Información, es - al menos entre los años 2008 y 2011 - la más baja en relación con el resto de áreas disciplinarias. Este dato, no permite establecer conclusiones definitivas, pero aporta perspectiva para comprender el lugar de la disciplina en el contexto general del apoyo público al desarrollo científico en el país.

3 El listado completo de los proyectos se puede consultar en http://nubr.co/xKhXiY 


\section{DISERTACIONES}

ESTUDIOS

Anuario electrónico de estudios en Comunicación Social

ISSN: 1856-9536

Doi: dx.doi.org/10.12804/disertaciones.09.02.2016.05

Volumen 9, Número 2 / julio-diciembre 2016

Versión PDF para imprimir desde

http://revistas.urosario.edu.co/index.php/disertaciones

Tabla 1. Tasa de adjudicación proyectos Fondecyt aprobados, periodo 2008-2011

\begin{tabular}{|c|c|c|c|c|c|c|c|}
\hline Año 2008 & $\begin{array}{c}\text { Ciencias } \\
\text { Naturales }\end{array}$ & $\begin{array}{c}\text { Ingeniería y } \\
\text { tecnología }\end{array}$ & $\begin{array}{l}\text { Ciencias } \\
\text { médicas y de } \\
\text { la salud }\end{array}$ & $\begin{array}{c}\text { Ciencias } \\
\text { agrícolas }\end{array}$ & $\begin{array}{l}\text { Ciencias } \\
\text { Sociales }\end{array}$ & Humanidades & Total \\
\hline Postulados & 311 & 149 & 116 & 84 & 260 & 114 & 1.034 \\
\hline Adjudicados & 168 & 61 & 47 & 33 & 75 & 49 & 433 \\
\hline $\begin{array}{l}\text { Tasa de } \\
\text { adjudicación }\end{array}$ & $55 \%$ & $43 \%$ & $44 \%$ & $42 \%$ & $30 \%$ & $45 \%$ & $44 \%$ \\
\hline \multicolumn{8}{|l|}{ Año 2009} \\
\hline Postulados & 328 & 142 & 111 & 79 & 252 & 125 & 1037 \\
\hline Adjudicados & 157 & 55 & 49 & 25 & 75 & 44 & 405 \\
\hline $\begin{array}{l}\text { Tasa de } \\
\text { adjudicación }\end{array}$ & $49 \%$ & $40 \%$ & $47 \%$ & $34 \%$ & $30 \%$ & $36 \%$ & $40 \%$ \\
\hline \multicolumn{8}{|l|}{ Año 2010} \\
\hline Postulados & 361 & 151 & 106 & 78 & 226 & 122 & 1.044 \\
\hline Adjudicados & 174 & 51 & 46 & 29 & 67 & 46 & 413 \\
\hline $\begin{array}{l}\text { Tasa de } \\
\text { adjudicación }\end{array}$ & $49 \%$ & $34 \%$ & $46 \%$ & $38 \%$ & $30 \%$ & $38 \%$ & $40 \%$ \\
\hline \multicolumn{8}{|l|}{ Año 2011} \\
\hline Postulados & 385 & 139 & 94 & 84 & 248 & 110 & 1060 \\
\hline Adjudicados & 192 & 66 & 55 & 35 & 96 & 59 & 503 \\
\hline $\begin{array}{l}\text { Tasa de } \\
\text { adjudicación }\end{array}$ & $51 \%$ & $50 \%$ & $60 \%$ & $44 \%$ & $41 \%$ & $56 \%$ & $49 \%$ \\
\hline
\end{tabular}

Fuente: Adaptación a partir del informe "Compendio estadístico 2008-2011" de la Comisión

Nacional de Ciencia y Tecnología (Conicyt).

Más allá de estos datos, si se hace el ejercicio de poner en relación los 45 proyectos aprobados en Ciencias de la Comunicación e Información con otras disciplinas o áreas del conocimiento, se puede observar que el total de iniciativas aprobadas en el área corresponden solo al 0,35\% de los 12684 proyectos Fondecyt Regular aprobados entre 1982 y 2014.

Como se recoge en la figura 1, hasta 2014, el año 2011 -junto con 2008- ha sido el que, en que Ciencias de la Comunicación e Información, ha tenido un mayor número de proyectos Fondecyt aprobados, fueron 6, el 1,2\% del total. Asimismo, dichas 6 investigaciones corresponden al 35,3\% de los proyectos de Sociología de aquel año, donde se enmarca el objeto de estudio dentro del área de Ciencias Sociales y Humanidades. No obstante, esa cifra disminuyó durante los años siguientes, alcanzando el 11,5\% en 2012, el 12\% en 2013 y el 17\% en 2014.

Ya en cuanto al presupuesto otorgado año a año a los proyectos aprobados, Biología, Ingeniería y Medicina se repiten como las disciplinas que obtienen un mayor porcentaje en relación con el total. Entre las tres, en 2013 obtuvieron el 49,5\% de los 23928586 pesos chilenos entregados para el primer año de ejecución de las investigaciones, 


\section{DISERTACIONES}

ESTUDIOS

Anuario electrónico de estudios en Comunicación Social

ISSN: 1856-9536

Doi: dx.doi.org/10.12804/disertaciones.09.02.2016.05

Volumen 9, Número 2 / julio-diciembre 2016

Versión PDF para imprimir desde

http://revistas.urosario.edu.co/index.php/disertaciones

mientras que Ciencias de la Comunicación e Información obtuvo el 0,23\%. Porcentaje incluso menor al 0,32\% de 2012 y al 0,66\% de 2011.

De esta forma, al analizar las cifras de las investigaciones sobre Ciencias de la Comunicación e Información realizadas con fondos públicos en Chile entre 1982 y 2014, y comparándolas con otras disciplinas, se observa que hay enormes diferencias. Tanto en número de proyectos aprobados y llevados a cabo, como en el presupuesto otorgado, la Comunicación está muy por detrás de otras disciplinas pertenecientes a las áreas de Ciencias Naturales y Exactas y Tecnologías.

\subsection{Proyectos en Comunicación e Información: principales tendencias}

Tras haber identificado los proyectos en el campo de la Comunicación financiados por Fondecyt, y ubicar su posición relativa en relación con otras áreas del saber, como último punto de los objetivos y resultados se caracterizarán las principales tendencias de las iniciativas financiadas, considerando temáticas y objetos de estudio, además de investigadores responsables y distribución institucional.

\section{Instituciones e investigadores ¿Dónde y quiénes realizan la investigación?}

Comenzando por la localización geográfica de las instituciones de los investigadores responsables de cada proyecto financiado, se ve una clara concentración en centros de estudios ubicados en la Región Metropolitana del país. Este resultado, lejos de ser sorprendente, ratifica una tendencia nacional caracterizada por el centralismo entorno a la ciudad de Santiago y región Metropolitana, capital administrativa y política del país, que concentra además la mayor cantidad de población y, en el caso que interesa, centros de educación superior.

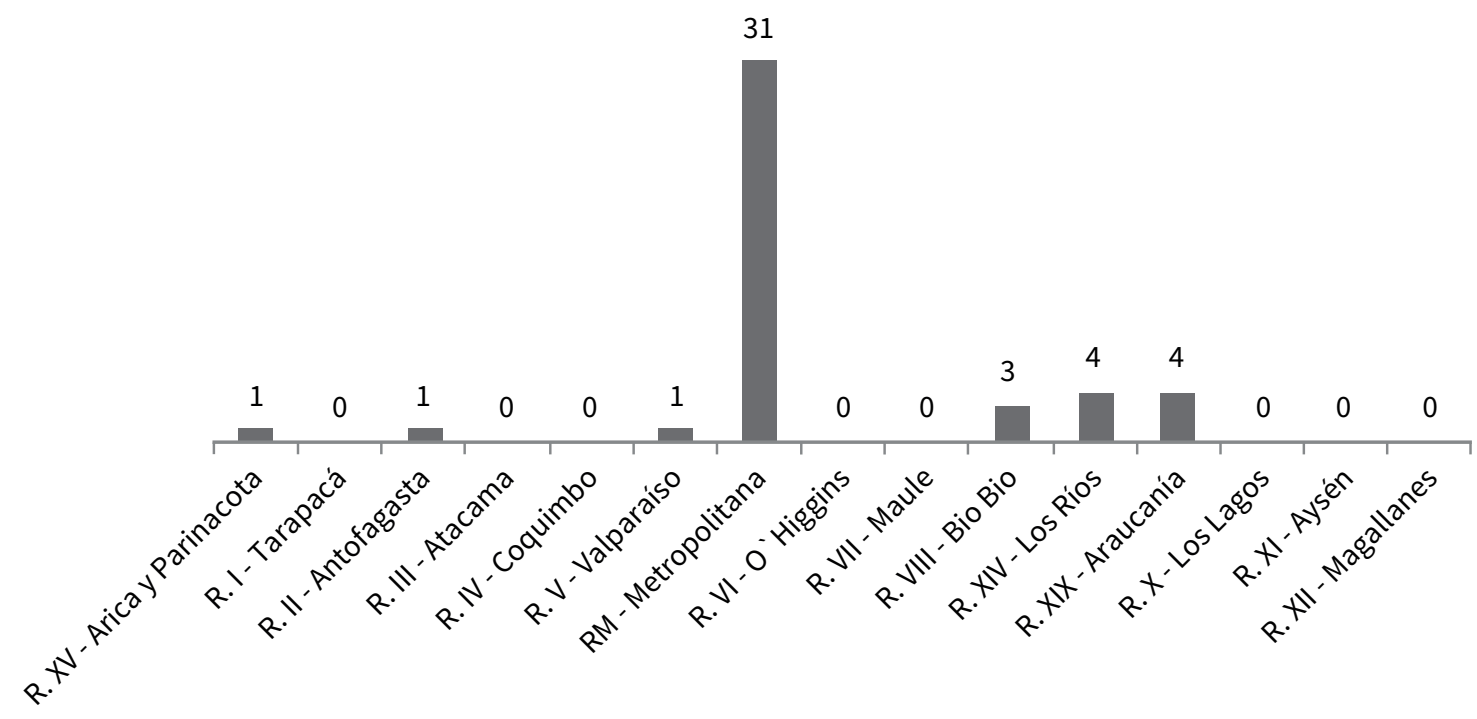

Figura 2. Proyectos Fondecyt aprobados en el campo de la Comunicación por región (1982-2014) 


\section{DISERTACIONES}

ESTUDIOS

Anuario electrónico de estudios en Comunicación Social

ISSN: 1856-9536

Doi: dx.doi.org/10.12804/disertaciones.09.02.2016.05

Volumen 9, Número 2 / julio-diciembre 2016

Versión PDF para imprimir desde

http://revistas.urosario.edu.co/index.php/disertaciones

La relación entre concentración de proyectos y presencia de universidades en la zona metropolitana es altamente equivalente: el 68,2\% de las casas de estudio que ofertan la carrera de periodismo en el país corresponden a universidades ubicadas en la Región Metropolitana; y el 68,8\% de los proyectos Fondecyt Regulares aprobados en la disciplina fueron adjudicados a investigadores que, al menos en el momento de la postulación, lo hicieron con el patrocinio de una institución de la Región Metropolitana ${ }^{4}$.

Tabla 2. Proyectos Fondecyt Regular aprobados en el campo de la Comunicación por universidad entre 1982-2014

\begin{tabular}{|c|c|c|c|c|}
\hline & Institución & Tipo de institución & Región & $\begin{array}{c}\mathrm{N}^{\circ} \text { de } \\
\text { proyectos }\end{array}$ \\
\hline 1 & Pontificia Universidad Católica de Chile & Universidad tradicional & Metropolitana & 16 \\
\hline 2 & Universidad Austral de Chile & Universidad tradicional & Los Ríos & 4 \\
\hline 3 & Universidad de Santiago de Chile & Universidad tradicional & Metropolitana & 3 \\
\hline 4 & Universidad de la Frontera & Universidad tradicional & Araucanía & 4 \\
\hline 5 & Universidad de Chile & Universidad tradicional & Metropolitana & 4 \\
\hline 6 & Universidad Diego Portales & Universidad privada & Metropolitana & 3 \\
\hline 7 & Universidad de Concepción & Universidad tradicional & Bío Bío & 2 \\
\hline 8 & $\begin{array}{l}\text { Universidad Academia de Humanismo } \\
\text { Cristiano }\end{array}$ & Universidad privada & Metropolitana & 2 \\
\hline 9 & $\begin{array}{l}\text { Universidad Metropolitana de Ciencias de la } \\
\text { Educación }\end{array}$ & Universidad tradicional & Metropolitana & 1 \\
\hline 10 & Universidad del Bío-Bío & Universidad tradicional & Bío Bío & 1 \\
\hline 11 & Universidad de Tarapacá & Universidad tradicional & Arica y Parinacota & 1 \\
\hline 12 & Universidad Católica del Norte & Universidad tradicional & Antofagasta & 1 \\
\hline 13 & Pontificia Universidad Católica de Valparaíso & Universidad tradicional & Valparaíso & 1 \\
\hline 14 & Educación y Comunicaciones & $\begin{array}{l}\text { Organización no } \\
\text { Gubernamental }\end{array}$ & Metropolitana & 1 \\
\hline 15 & $\begin{array}{l}\text { Centro de Comunicación y Cultura Para el } \\
\text { Desarrollo }\end{array}$ & $\begin{array}{l}\text { Organización no } \\
\text { Gubernamental }\end{array}$ & Metropolitana & 1 \\
\hline
\end{tabular}

Fuente: elaboración propia a partir de bases de datos, de acceso público, del Fondo de Desarrollo Científico y Tecnológico (Fondecyt) del Estado de Chile.

4 Los proyectos Fondecyt se asignan al investigador, no a la institución, por lo que si el investigador responsable cambia de universidad, el proyecto se traslada con él. Por lo tanto, este dato, considera solo la institución patrocinante de al momento de la postulación. 


\section{DISERTACIONES}

Estudios

Anuario electrónico de estudios en Comunicación Social

ISSN: 1856-9536

Doi: dx.doi.org/10.12804/disertaciones.09.02.2016.05

Volumen 9, Número 2 / julio-diciembre 2016

Versión PDF para imprimir desde

http://revistas.urosario.edu.co/index.php/disertaciones

Esta concentración la vemos también en dos variables: una general -tipo de universidades-y otra específica -institución que ostenta el mayor número de proyectos-. En la primera de ellas, la arista general, se observa un marcado e inapelable predominio de las universidades tradicionales, por sobre las privadas.

Para quien no esté familiarizado con el sistema de educación superior chileno, valga la pena aclarar que para el directorio de universidades del Ministerio de Educación de Chile, existen tres categorías para agrupar los planteles universitarios en el país: universidad estatal, universidad particular con aporte estatal y universidad privada. Los primeros dos grupos reúnen 25 instituciones, creadas o reconocidas con anterioridad a 1981 o que derivan de aquellas, las que son denominadas como universidades tradicionales reciben aporte directo del Estado y pertenecen al Consejo de Rectores de las Universidades Chilenas (СRUCH). La labor de este organismo colegiado consiste en coordinar la labor universitaria en el país, siendo responsable, por ejemplo, del establecimiento de un sistema de selección y admisión de estudiantes a las universidades que lo conforman, que desde 2003 corresponde a la Prueba de Selección Universitaria (PsU).

En tanto, actualmente en Chile existen más de cuarenta universidades privadas, las que fueron creadas a partir de 1981, tras la entrada en vigencia de la Ley Orgánica Constitucional de Enseñanza durante la dictadura de Augusto Pinochet. Dichas instituciones son creadas por el sector privado, tienen sus propios reglamentos y la mayoría de ellas no tiene un sistema de selección y admisión dependiente de la psu.

Tomando esta caracterización como marco, se observa que el lugar protagónico en la adjudicación de proyectos de Fondecyt se concentra en las universidades tradicionales pertenecientes al cruch, con una cifra de proyectos adjudicados (38) muy superior a la de las universidades privadas (5), y a la de organizaciones no gubernamentales (2). Estas últimas, además, se adjudicaron proyectos muy al inicio del periodo observado - María de la Luz Hurtado, del Centro de Comunicación y Cultura para el Desarrollo (1987), con el proyecto "La televisión en Chile"; y Fernando Ossandón Correa, de Educación y Comunicaciones (ECO) (1993), con el estudio "Hacia un modelo de comunicación municipal participativa, viable y eficiente. Investigación aplicada y experimental en comunas urbanas pobres"-, tendencia que, como se revisó en la caracterización histórica de la investigación en Comunicación en el país, coincide con la llegada de la transición a la democracia, y el declive -en pos de las universidades y el aparato público- de las ONG como espacios de generación de conocimiento. 


\section{DISERTACIONES}

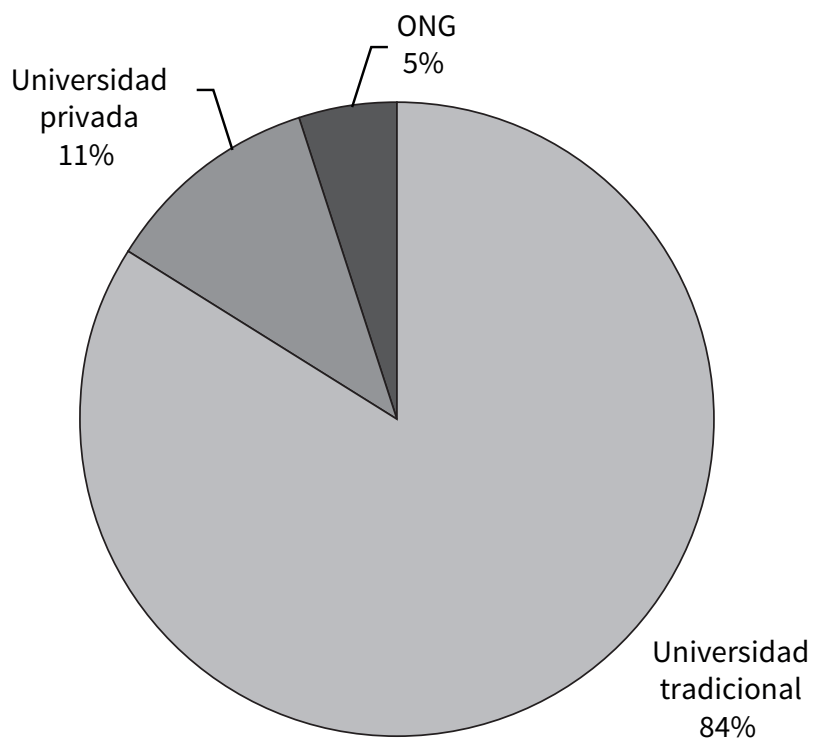

Figura 3. Distribución de las universidades en Chile, según su financiamiento

En esta distribución de universidades, otro dato llama la atención: la concentración de los proyectos adjudicados en la Pontificia Universidad Católica de Chile, que reúne el 35,5\% del total de proyectos asignados, y el 42,1\%, si se considera el subtotal asignado a universidades tradicionales. 


\section{DISERTACIONES}

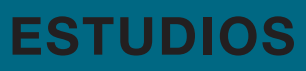

Anuario electrónico de estudios en Comunicación Social

ISSN: 1856-9536

Doi: dx.doi.org/10.12804/disertaciones.09.02.2016.05

Volumen 9, Número 2 / julio-diciembre 2016

Versión PDF para imprimir desde
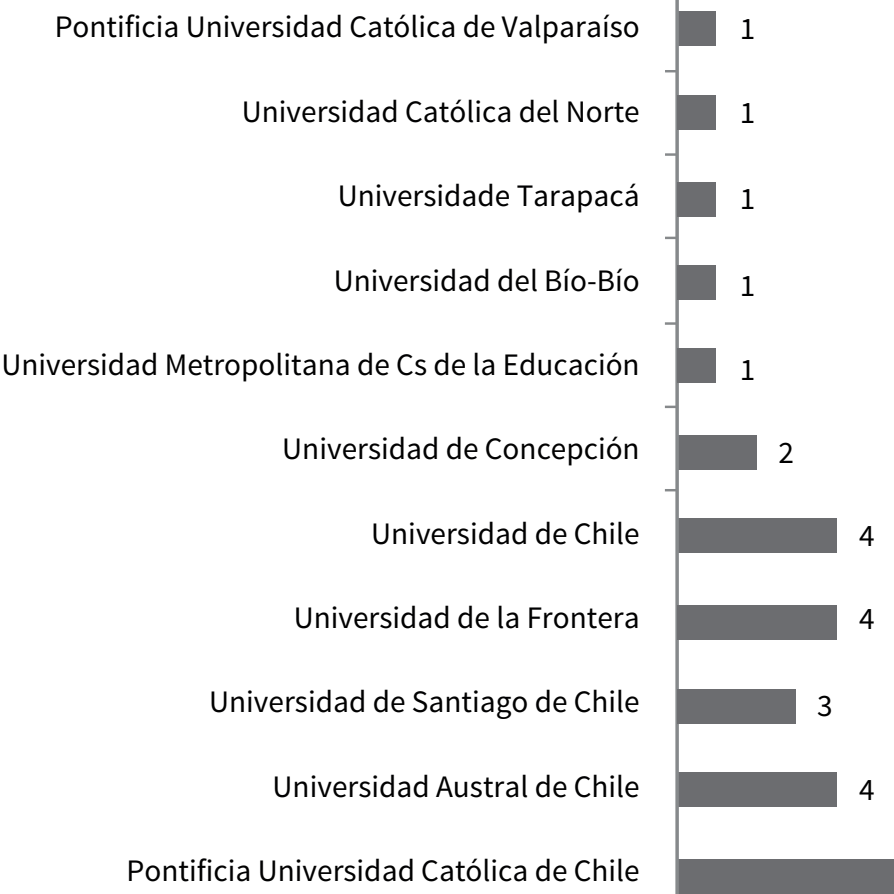

Pontificia Universidad Católica de Chile

Figura 4. Distribución proyectos en universidades tradicionales

El único criterio que rompe la tendencia de concentración corresponde a los investigadores responsables de los proyectos: los 45 proyectos de la muestra se distribuyen en 31 investigadores principales. De estos, la gran mayoría (22 investigadores, es decir el 70,9\% del total) figura en las bases de datos como responsable de solo un proyecto. 


\section{DISERTACIONES}

ESTUDIOS

Anuario electrónico de estudios en Comunicación Social

ISSN: 1856-9536

Doi: dx.doi.org/10.12804/disertaciones.09.02.2016.05

Volumen 9, Número 2 / julio-diciembre 2016

Versión PDF para imprimir desde

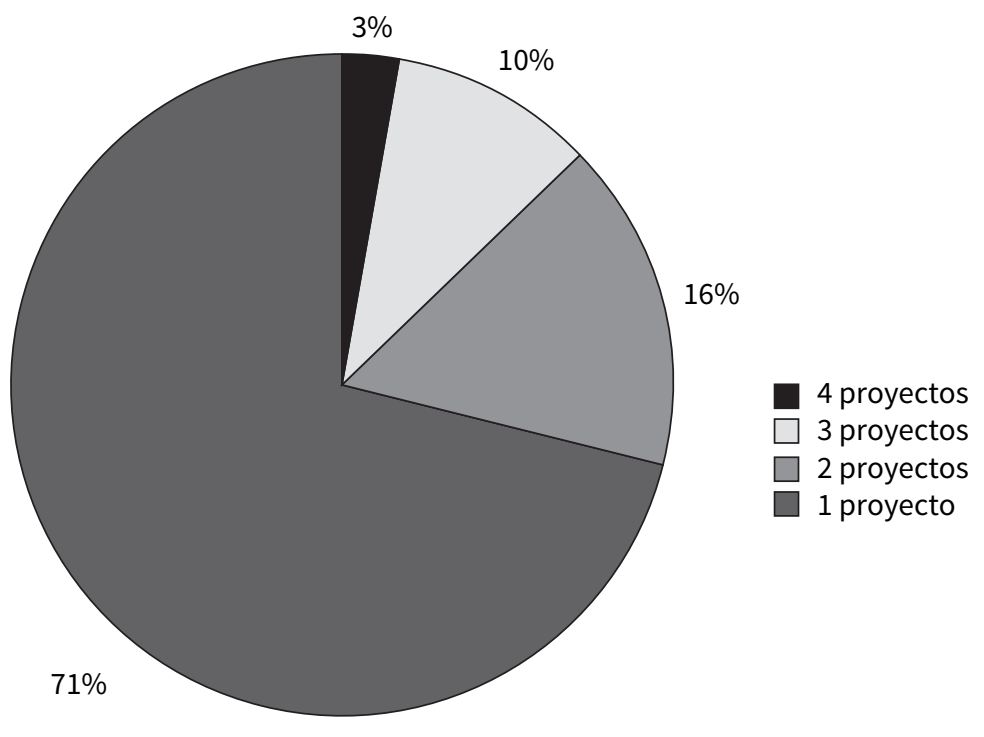

Figura 5. Distribución de investigadores por número de proyectos a cargo

De los 9 académicos que figuran como investigadores responsables en más de un proyecto, 5 lo son en dos (los Drs. Carlos del Valle, Claudia Mellado, Cristian Antoine, Pablo Villarroel y Rodrigo Browne), tres en tres (los Drs. Bernardo Amigo, Sergio Godoy y William Porath), y solo una también en cuatro iniciativas (Dra. María Soledad Puente). Es interesante indicar que mientras el Dr. Amigo es académico de la Universidad de Chile, los Drs. Gody, Porath y Puente son académicos de la Facultad de Comunicaciones de la Pontificia Universidad Católica de Chile, institución que, como ya se ha reseñado, concentra la mayor cantidad de proyectos financiados por Fondecyt Regular ${ }^{5}$.

\section{Temas y objetos de estudio: ¿qué se investiga?}

En los 45 proyectos de la muestra, se observó una marcada tendencia al desarrollo de investigaciones que abordan, como tema central o soporte de análisis, algún aspecto de los medios o su industria: 32 proyectos, lo que equivale al $71,1 \%$ del total de iniciativas financiadas en al área.

5 Cabe recordar que estos datos corresponden solo hasta 2014, pero que ya se verían modificados con los resultados de Fondecyt Regular 2015, donde -y considerando solo a los investigadores mencionados en este párrafo- fueron aprobados proyectos de los Drs. Carlos del Valle, Claudia Mellado y María Soledad Puente. 


\section{DISERTACIONES}

\section{ESTUDIOS}

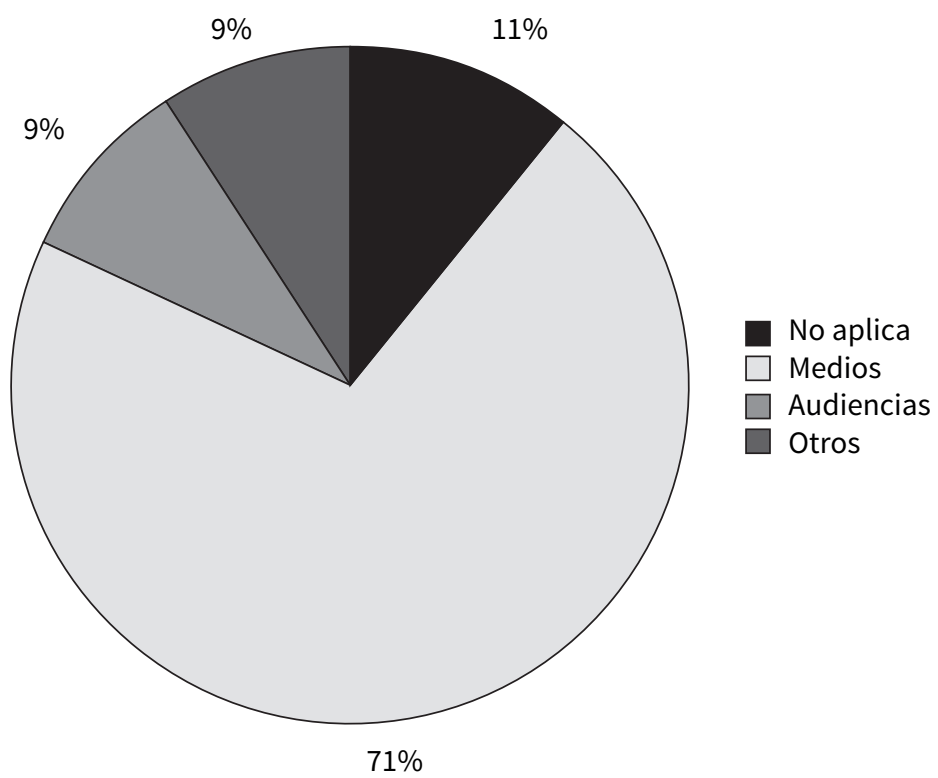

Figura 6. Temáticas centrales de los proyectos Fondecyt realizados dentro de la disciplina Ciencias de la Comunicación e Información

El segundo soporte de estudio prioritario - aunque de manera muy marginal-corresponde a las audiencias (no mediadas por los medios) con cuatro proyectos ( $9 \%$ de la muestra): 2 centrados en la recepción de la divulgación de la ciencia y 2 en el consumo cultural de los museos. El resto de los estudios - que están categorizados como "otros"- considera soportes de investigación heterogéneos, y observados solo en un proyecto como el propio campo profesional del periodismo en Chile, publicidad, formación inicial docente de maestros en el área de lenguaje desde la perspectiva de la edu-comunicación y modelos institucionales de comunicación municipal (institución de gobierno local equivalente a los ayuntamientos españoles) en zona urbanas pobres.

Además, del total de proyectos, 5 iniciativas fueron categorizadas como "no aplica" pues, y a pesar de haberse aprobado como investigaciones vinculadas a la subdisciplina de Ciencias de la Comunicación e Información, sus temáticas corresponden más bien a áreas de educación (tres proyectos) e ingeniería (dos proyectos), y sin relación, al menos directa o explícita, con el campo del periodismo, la comunicación o la información.

Entre los 32 proyectos vinculados con los medios, la atención principal, como objeto de estudio, se centra en la televisión. En total, 14 investigaciones la consideran como soporte de estudio; 11 (38\%) de manera exclusiva, y $3(10 \%)$ en conjunto y comparación con la prensa escrita. 


\section{DISERTACIONES}

ESTUDIOS

Anuario electrónico de estudios en Comunicación Social

ISSN: $1856-9536$

Doi: dx.doi.org/10.12804/disertaciones.09.02.2016.05

Volumen 9, Número 2 / julio-diciembre 2016

Versión PDF para imprimir desde

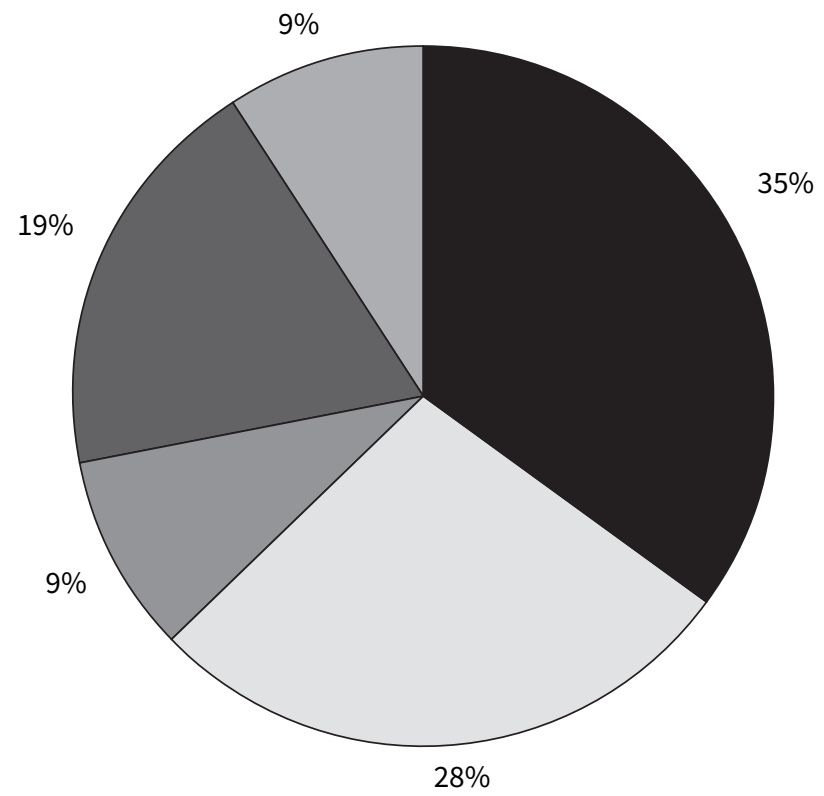

Sólo televisión

Sólo prensa escrita

$\square$ Prensa escrita y televisión

$\square$ Internet, medios digitales, TIC

Medios en general

Figura 7. Objeto de estudio de los proyectos Fondecyt vinculados a los medios

Esta última tipología de medios (prensa escrita) y en especial la prensa diaria, es el segundo soporte de investigación con mayor presencia entre los estudios de la muestra, donde 8 de los proyectos adjudicados se centran en esta de manera única, lo que corresponde al $28 \%$ de los 29 proyectos centrados en medios.

Otros soportes relevantes son los vinculados a Internet y medios digitales, y la industria mediática en general. A la luz de estos datos es interesante poner un punto de atención en el medio ausente: la radio, cuya observación no forma parte de ninguna de las investigaciones financiadas por Fondecyt, al menos durante el periodo analizado.

Más allá de los soportes en que se centra la recolección de datos de las diferentes investigaciones, las temáticas se distribuyen entre los proyectos de la muestra, en 12 temas de estudio diferentes, siendo el predominante el que se ha denominado como mensaje periodístico.

En esta categoría se han incluido todas aquellas investigaciones dedicadas, fundamentalmente, al análisis, reflexión y propuesta de mejora sobre el contenido y discurso de textos noticiosos. Forman parte de esta categoría temas como el uso de recursos melodramáticos en la generación de textos noticiosos y sus efectos en la valoración y comprensión de la información; periodismo intercultural y construcción de la noticia; elaboración de un modelo de acción periodística a partir de la cobertura noticiosa del terremoto ocurrido en Chile el 27 de febrero de 2010; el discurso de la prensa sobre justicia/injusticia en relación con el conflicto chileno-Mapuche; análisis de contenido de la prensa en relación con la propiedad de los medios; comparación de noticias judiciales y sentencias como productores de discursos; análisis de estéticas e imaginarios relacionados con la programación de cine en la tv; análisis sobre el imaginario estado-nación e iglesia publicadas en las críticas literarias y periodísticas en el diario El Mercurio durante el siglo xx y estudios sobre la calidad informativa y su relación con la comprensión de historias periodísticas. 


\section{DISERTACIONES}

ESTUDIOS

Anuario electrónico de estudios en Comunicación Social

ISSN: 1856-9536

Doi: dx.doi.org/10.12804/disertaciones.09.02.2016.05

Volumen 9, Número 2 / julio-diciembre 2016

Versión PDF para imprimir desde

Comunicación para el cambio social y desarrollo

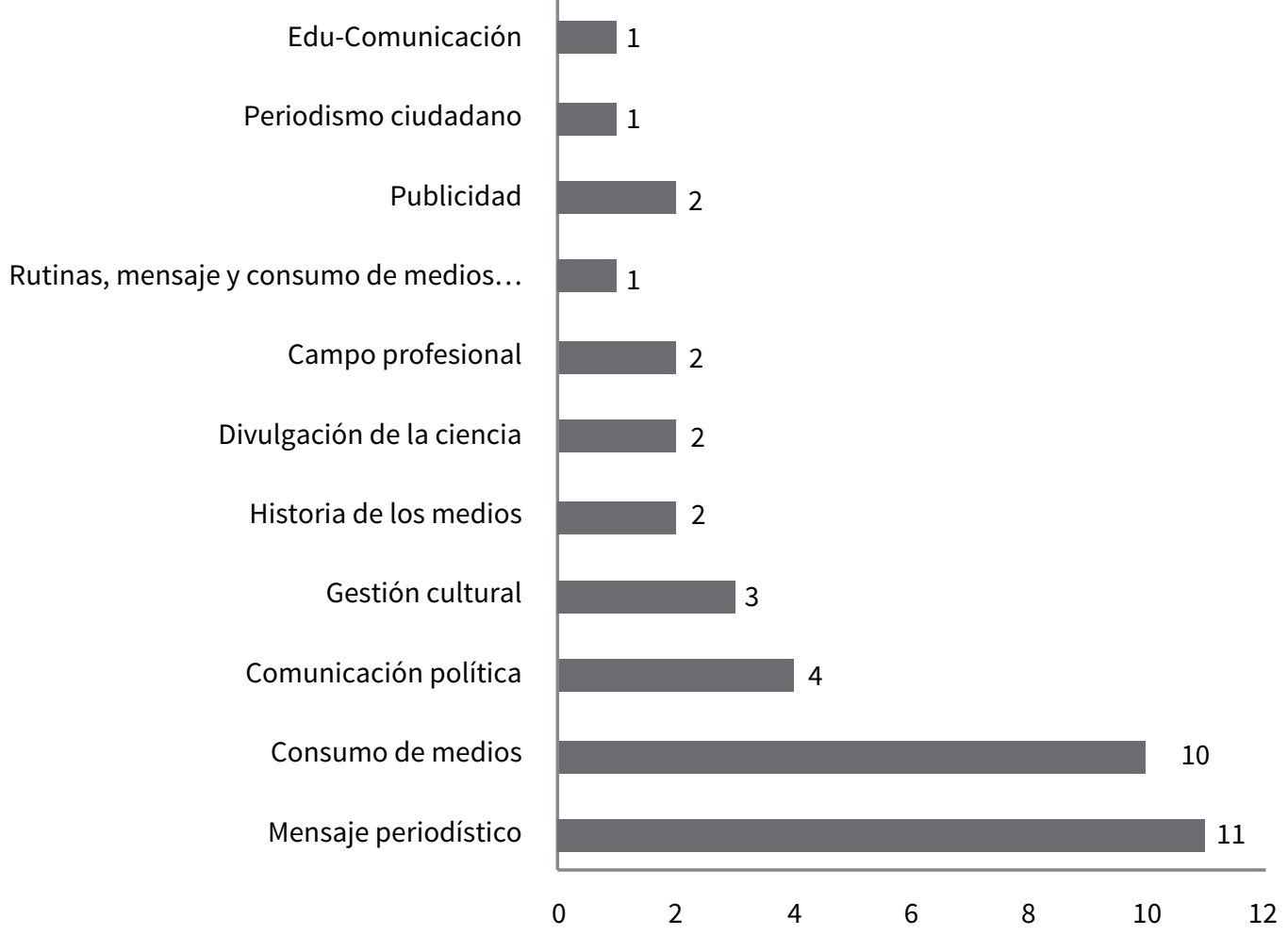

Figura 8. Otras temáticas centrales de los proyectos Fondecyt realizados dentro de la disciplina Ciencias de la Comunicación e Información

La segunda de las temáticas que concentra mayor interés es la relacionada con el consumo de medios, donde se ubican 10 proyectos, vinculados con el uso de Internet y con el consumo de televisión (recepción y representación de jóvenes en el telediario; jóvenes y discursos sobre sexualidad y género; infancia, televisión y vida cotidiana y mediación parental y apropiación educativa de la Tv).

Por su parte, la comunicación política, como temática, se observa en cuatro proyectos, centrados en la investigación de fenómenos como opinión pública y Agenda Setting; relación entre medios de comunicación y elites políticas en cuanto a sus estrategias de influencia, el uso político de las noticias deportivas y la evolución de las campañas presidenciales chilenas desde la llegada de la democracia.

\section{Conclusiones}

Este trabajo nació con el propósito de analizar y caracterizar la investigación vinculada al campo de la Comunicación en Chile que, entre 1982 y 2014, ha sido apoyada por la principal fuente de financiamiento público para 


\section{DISERTACIONES}

ESTUDIOS

Anuario electrónico de estudios en Comunicación Social

ISSN: $1856-9536$

Doi: dx.doi.org/10.12804/disertaciones.09.02.2016.05

Volumen 9, Número 2 / julio-diciembre 2016

Versión PDF para imprimir desde

el desarrollo de la ciencia y tecnología en el país, Conicyt, y uno de sus más relevantes concursos públicos, Fondecyt Regular. Con esta elección, no se desconoce la existencia de otras fuentes de apoyo y financiamiento a la generación de conocimiento en el área, pero se pone el acento en su relevancia en la estructura de la comunidad científica nacional.

A partir de este objetivo general, se fue avanzando en la obtención de datos más específicos que pudieran aportar a esta caracterización: se identifican los proyectos adjudicados dentro del área de Ciencias de la Comunicación durante el periodo estudiado (45 en total); se ubica la posición relativa de este total en relación con otras disciplinas o áreas de conocimiento; finalmente, se realizó una revisión descriptiva de las principales tendencias en cuanto a temáticas, objetos e instituciones responsables, presentes dentro de los proyectos financiados en el campo. Con base en todos estos elementos, se quiere finalizar con algunas reflexiones generales que surgen tras la revisión de los datos.

Se debe poner la atención en el restringido lugar que, tanto en cantidad de proyectos financiados como en los recursos destinados, ocupa la investigación del campo de la Comunicación en relación con otras áreas disciplinares. Esta tendencia, que ya reseñaba Del Valle (2004b) hace una década al evidenciar la escasa proporción de la investigación formal en el campo de las ciencias de la comunicación e información y la falta de incentivo por parte del Estado, se mantiene en la actualidad. Ya se ha visto que en el periodo analizado la investigación apoyada públicamente por medio de este fondo representa solo el 0,35\% del total de proyectos financiados. Faltan antecedentes para dimensionar el estado del arte global de la investigación en Comunicación en el país - desafíos para futuros estudios-, pero, estos antecedentes, aunque acotados y limitados, dan pistas sobre la relevancia que se da a la disciplina frente a otros saberes.

Dejando de lado esta especie de "lamento" o reclamo disciplinar para poner foco en los proyectos propiamente tal, se observa, como gran característica y tendencia, la concentración de la investigación. Este atributo se hace patente en diferentes variables: instituciones que encabezan las investigaciones financiadas, localización de estas y temáticas y objetos de estudios privilegiados.

En lo que se ha denominado como distribución institucional, ya se evidencia una concentración geográfica en la zona metropolitana capital de Chile, lo que no es sino un reflejo del fuerte centralismo que caracteriza a Chile, y que es una queja constante en otras dimensiones de la vida social, económica y política. "Santiago es Chile", versa un dicho popular que, de acuerdo con los datos, se ve reflejado también en los espacios académicos desde donde se genera conocimiento en el área.

En cuanto a las universidades que llevan a cabo los proyectos adjudicados por Fondecyt Regular, hay una doble concentración. Por una parte, se ve que es solo una la institución la que encabeza la mayor cantidad de investigaciones, la Pontificia Universidad Católica de Chile, la misma que cuenta con la revista del área con mejor indexación y el programa de doctorado con más trayectoria en el país (y, de hecho, único hasta 2015). Estos datos son parecen interesantes de relacionar pues, se habla de una comunidad académica que ha proyectado el desarrollo de la disciplina considerando sus distintas variables: formación de pre- y posgrado, desarrollo de nuevo conocimiento y, además, difusión de este.

Por otra parte, la distribución institucional de la investigación muestra una concentración también en cuanto al tipo de universidad, siendo las denominadas "tradicionales" el espacio prioritario de la actividad científica. En este punto, se cree necesario recordar que uno de los objetivos de la reforma al sistema educacional chileno,

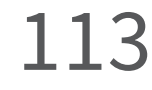




\section{DISERTACIONES}

ESTUDIOS

Anuario electrónico de estudios en Comunicación Social

ISSN: 1856-9536

Doi: dx.doi.org/10.12804/disertaciones.09.02.2016.05

Volumen 9, Número 2 / julio-diciembre 2016

Versión PDF para imprimir desde

http://revistas.urosario.edu.co/index.php/disertaciones

implementada en 1981, y que permitió la creación de las universidades privadas, fue estimular la competencia entre las instituciones universitarias. Sin embargo, a la luz de los resultados de la muestra analizada, se puede concluir que en esta "competencia" seguirían teniendo un predominio las universidades tradicionales, al menos, en lo referente a la masa crítica de sus cuerpos académicos. Esto, en el entendido y supuesto que el espacio universitario debiera caracterizarse por un quehacer académico vinculado a la generación de conocimiento que aporte al desarrollo disciplinar, y no solo a la reproducción de este. Se entiende que este punto es altamente cuestionable y debatible, sobre todo en base a la noción del quehacer académico en que se sustentó la concepción de universidad y su rol social para esta investigación.

Curiosamente, la única variable en que no se observó concentración es en el nombre específico de los investigadores principales de los proyectos de la muestra, donde se vio que menos de la mitad que aparece es responsable de más de una iniciativa. Si bien, sería necesario analizar las trayectorias de investigación de cada uno de ellos, para establecer la continuidad -o no- de su trabajo, no deja de ser interesante la aparentemente escasa configuración o consolidación de programas de investigación más permanentes, a excepción de aquellos que sí han contado con más de una adjudicación en este fondo concursable, proyectando así una línea de estudio más estable en el tiempo. Tal es el caso, por ejemplo, del World Internet Project-Chile encabezado por el Dr. Sergio Godoy, o los estudios sobre Valor Agregado Periodístico (VAP) encabezados por la Dra. María Soledad Puente. ¿Qué sucedió con las otras propuestas adjudicadas? ¿Tuvieron alguna proyección? Nuevas preguntas que permiten continuar abriendo caminos para futuras meta-investigaciones sobre el campo de la Comunicación en Chile.

Salvo esta excepción, y volviendo a la tendencia generalizada que se ha reseñado, nuevamente se observa concentración de la investigación en lo referido a las temáticas y objetos de estudio prioritarios, resultado caracterizado por la hegemonía de los medios, tanto en las temáticas como en los soportes u objetos de estudio materiales en que se basan las investigaciones. Esta tendencia no es una sorpresa en el marco del campo de la Comunicación, donde el "mediacentrismo" es indiscutible en la fundación y desarrollo de la disciplina. Sin embargo, sí es interesante acotar la invisibilización de la radio, al menos desde el fondo analizado. Se aventura por una explicación desde la factibilidad de acceso a corpus de análisis, sobre todo si se considera la tendencia a la realización de estudios sobre mensaje periodístico, tarea que se facilita con fuentes de archivo como hemerotecas o archivos digitales, pero que es menos sistematizada - en especial antes del podcast- en el caso de la radio.

Finalmente, es necesario dedicar unas palabras al lugar que Fondecyt otorga a las distintas áreas de conocimiento en su ordenamiento de postulación, y donde el campo -y aunque nominalmente se le reconoce el nivel de ciencia de la comunicación e información- es comprendido como una subdisciplina dependiente de la Sociología, y en el mismo rango de áreas muy especializadas como sociología de las organizaciones formales, sociología urbana y rural o sociología del trabajo. Se cree encontrar en este dato algunas pistas de los desafíos o caminos pendientes de la comunidad académica: avanzar en su consolidación o, al menos, visibilización y valoración.

\section{Referencias}

1. Asesorías para el Desarrollo (2012). Estudio de percepción y satisfacción con políticas de Conicyt entre los investigadores chilenos. Santiago: Conicyt, Ministerio de Educación. Recuperado de: http://www.conicyt. cl/blog/2013/05/estudio-percepcion-satisfaccion-politicas-conicyt/

\section{4}




\section{DISERTACIONES}

Estuolos

Anuario electrónico de estudios en Comunicación Social

ISSN: $1856-9536$

Doi: dx.doi.org/10.12804/disertaciones.09.02.2016.05

Volumen 9, Número 2 / julio-diciembre 2016

Versión PDF para imprimir desde

2. Avendaño, C. (1998). Transformaciones en la investigación en comunicación: el caso de Chile. Reflexiones Académicas, 11, 45-55.

3. Bourdieu, P. (1997). Espacio social y campo de poder. Barcelona: Anagrama.

4. Caldevilla D., \& Del Valle C. (2011). Análisis de las trayectorias investigadoras de las mujeres chilenas a partir de sus publicaciones científicas en idioma español (I parte). Madrid: Visión Libros.

5. Castellón, L. (2006). Estado de la investigación en Chile y la formación de los comunicadores en el ámbito de la investigación en comunicación. Presentado en vi Encuentro de la enseñanza e investigación de la comunicación en los países del Mercosur. Cátedra Unesco/Umesp de Comunicação para o Desenvolvimento Regional, Santa Cruz de la Sierra, Bolivia.

6. Catalán, C. (1989). Las ong y la investigación en comunicaciones en Chile: una aproximación preliminar. Taller de Cooperación al Desarrollo. Una puerta que se abre. Santiago: flacso.

7. Del Valle, C. (2004a). Metainvestigación de la comunicación en Chile. Tendencias y crítica. Temuco: Ediciones Universidad de la Frontera.

8. Del Valle, C. (2004b). Metainvestigación de la comunicación en Chile (1970-2003). Reflexiones y críticas desde la economía política de la comunicación. Revista Latinoamericana de Ciencias de la Comunicación, $1,126-133$.

9. Dittus, R. (2008). Cartografía de los Estudios mediales en Chile. Concepción: Ediciones Universidad Católica de la Santísima Concepción.

10. Galindo, J. (2009). Apuntes de historia de una Comunicología posible. Hipótesis de configuración y trayectoria. En J. Galindo, K. Cárdenas, \& M. Rizo, Comunicología en Construcción (pp. 95-119). Ciudad de México: Universidad Autónoma de México.

11. González, G. (2001). Estado actual de la enseñanza del periodismo en Chile. Recuperado de http://www. periodismo.uchile.cl/asepecs/presentggonzhtm.htm

12. Jeldres, C. (2014). Hacia un estado del arte de la investigación en comunicación en Chile. (Tesis de maestría no publicada, Universidad Diego Portales, Santiago, Chile).

13. Lazcano-Peña, D. (2007). Investigación en Comunicación Social en Chile: configurando el campo nacional. En P. Santander (Ed.) Los medios en Chile: voces y contextos (pp. 121-147). Valparaíso: Ediciones Universitarias de Valparaíso S.A.

14. Mattelart, A., \& Mattelart, M. (1995). Historia de las Teorías de la Comunicación. Barcelona: Paidós.

15. McQuail, D. (1991). Introducción a la teoría de la comunicación de masas. Barcelona: Paidós.

16. Moragas, M. (2011). Interpretar la comunicación. Estudios sobre medios en América y Europa. Barcelona: Editorial Gedisa, S.A.

17. Munizaga, G., \& Rivera, A. (1983). La investigación en Comunicación Social en Chile. Lima: Desco, Centro de Estudios y Promoción del Desarrollo.

18. Olivares, C. (2011). Objetos de estudio de investigaciones de pregrado realizadas en la Escuela de Periodismo pucv. (Trabajo de maestría no publicado, Pontificia Universidad Católica de Valparaíso, Valparaíso, Chile).

19. Otero, E. (1996). Contenidos temáticos de la formación en Comunicación. Talón de Aquiles 4, 38-40. 


\section{DISERTACIONES}

ESTUDIOS

Anuario electrónico de estudios en Comunicación Social

ISSN: 1856-9536

Doi: dx.doi.org/10.12804/disertaciones.09.02.2016.05

Volumen 9, Número 2 / julio-diciembre 2016

Versión PDF para imprimir desde

http://revistas.urosario.edu.co/index.php/disertaciones

20. Parada, J. (2010). Universidades públicas y privadas: Un enfoque tridimensional. Santiago: Centro de Estudios Públicos - cEP. Recuperado de http://www.cepchile.cl/1_4745/doc/universidades_publicas_y_privadas_un_enfoque_tridimensional.html\#.Vh3k-_l_Okq

21. Rodrigo-Alsina, M. (2001). Teorías de la comunicación: ámbitos, métodos y perspectivas. Barcelona: Universidad Autónoma de Barcelona, Servei de Publicaciones.

22. Saperas, E. (2012). Comunicación mediática y sociedad. Manual de Teorías de la comunicación. Madrid: OMM Editorial.

23. Vasallo de Lopes, M. (2001). Reflexiones sobre el estatuto disciplinario del campo de la comunicación. En M. Vasallo de Lopes, \& R. Fuentes Navarro, Comunicación: Campo y Objeto de Estudio. Perspectivas Reflexivas Latinoamericanas (pp. 43-58). Tlaquepaque: Instituto Tecnológico y de Estudios Superiores de Occidente (ITESO).

24. Wolf, M. (1987). La investigación de la comunicación de masas. Crítica y perspectiva. Barcelona: Ediciones Paidós. 